\title{
The doctor-patient relationship in the context of the COVID-19 pandemic
}

\author{
DVânia Thais Silva Gomes ${ }^{1}$ \\ (iD) Roberto Oliveira Rodrigues ${ }^{2}$ \\ (iD) Raimundo Nonato Silva Gomes ${ }^{3}$ \\ (iD) Maria Silva Gomes ${ }^{4}$ \\ (DLarissa Vanessa Machado Viana \\ (iD) Felipe Santana e Silva ${ }^{6}$
}

\begin{abstract}
1. Departamento de Medicina, Universidade de Gurupi, Gurupi, TO, Brasil 2. Departamento de Medicina, Universidade Estadual do Maranhão, São Luiz, MA, Brasil 3. Centro de Ciências da Saúde, Universidade Federal do Rio de Janeiro, Rio de Janeiro, RJ, Brasil 4. Força Estadual de Saúde do Maranhão, São Luiz, MA, Brasil 5. Centro de Ciências da Saúde e do Desporto, Universidade Federal do Acre, Rio Branco, AC, Brasil 6. Centro de Ciências da Saúde. Universidade Estadual do Maranhão, São Luiz, MA, Brasil
\end{abstract}

http://dx.doi.org/10.1590/1806-9282.66.S2.7

KEYWORDS: Coronavirus Infections. Pandemics. Physician-Patient Relations.

The novel Coronavirus disease (COVID-19) pandemic has brought up complex and challenging issues in all areas of knowledge and in the social, political, economic, religious, cultural, and medical spheres. An important question to ask ourselves is: are doctors prepared to eliminate suffering and/or save lives in the current context?

The countless advances in biotechnology and biomedical engineering show promise in increasing people's life expectancy. Research is continuously being done in these areas; we learn more and more each day. However, the advances in technology have brought up an important discussion around the doctor-patient relationship (DPR). ${ }^{1}$
In addition to scientific advances, another important agent that affects DPR is telemedicine, which guarantees the possibility of remote assistance, but makes skin-to-skin contact, which is so necessary for medical conduct, impossible.

The implementation of social distancing has forced doctors to guarantee more humane and extremely high-quality care, as the disease has exposed the country to this situation of great suffering. Therefore, it is necessary to discuss the role of human relations, with an emphasis on DPR, in the development of medical practice. $^{2}$

On the other hand, in the context of hospitals, the intensive care unit (ICU) itself is already a widely 
complex unit and in serious need of technological apparatuses, especially in cases of complex diseases such as COVID-19. Patients with COVID-19 who are admitted to the ICU need extensive biotechnological investment to maintain vitality; additionally, they require great dedication from the doctors. However, DPR in the ICU was already a major challenge and with the outbreak of the COVID-19 pandemic the situation has become even worse, considering that the disease is highly contagious and there is a high mortality rate among "high-risk groups."”

The ICU, signaling the critical nature of patients' condition, causes great distress to patients' family members and the medical team itself. In the context of the COVID-19 pandemic, a patient in intensive care creates even more distress for the medical team and the patient's family, since the doctors do not have access to completely effective therapeutic means to alleviate the suffering of the patients and their relatives.

The DPR has always been based on the bond between the doctor and the patient and the doctor's sense of empathy; it is based on the medical oath to "save lives." Today, this principle has become fragile and powerless in the face of a giant that has already claimed many lives due to the collapse of the health system in many countries, including Brasil. ${ }^{4}$

Due to the collapse of the health system, it is up to the physician to decide who will have access to the scarce ICU beds. This situation favors the exponential growth of depressive, anxious, and phobic symptoms in medical professionals, especially among intensivists. Given these facts, we ask if the DPR will remain the same, and if humanized care - seeing the patient holistically - will still be the same in the near future.

Among the various aspects that make up the DPR, empathy deserves the most emphasis. Therapeutic adherence is based on the DPR since trust and mutual collaboration are required for the effectiveness of diagnostic and therapeutic processes, which are essential for good medical practice. As highlighted in Figure 1, DPR is based on multiple intersecting principles.

The evolutionary process of medical practice, which occurs naturally, has caused DPR to undergo numerous changes over the years, and empathy has not gone unaffected. Changes in behavior intrinsic to the pandemic constitute a landmark of great importance in DPR.

COVID-19, due to its highly infectious character, has overburdened healthcare systems and human resources, requiring the establishment of new modalities for patient care, such as telemedicine. However, it should be noted that the basic principle of DPR, as postulated by Hippocrates, may not be achieved through telemedicine (an alternative widely used during the pandemic). ${ }^{5}$

In addition to the numerous technical and ethical-legal questions raised by the pandemic, it must be made very clear that there is a great need for common sense in the DPR at present. Numerous alleged prophylactic and therapeutic measures emerge daily, and with them, new challenges to the DPR. ${ }^{4-5}$

The successful use of a technological resource to face this global challenge is likely to increase the

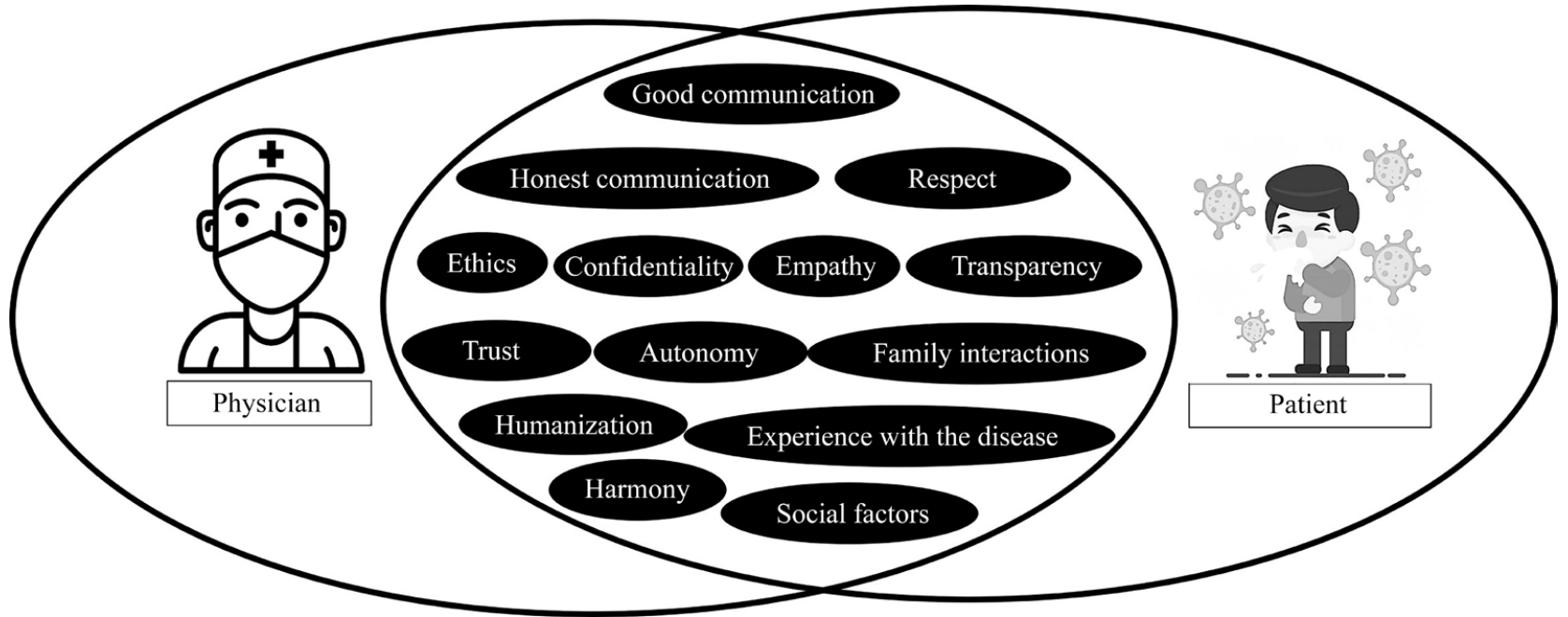


acceptance of such technologies. And, as already foreseen, any change (such as that caused by COVID19) causes also evolutionary changes in behavior in society. Therefore, DPR combined with new technologies can guarantee the scientific/humanistic apparatus necessary for the efficient care of patients with COVID-19.
Thus, the DPR continuum must coexist beyond the chaos in the public healthcare system; however, physicians' self-preservation must be an inalienable parameter in the daily practice of medicine.

\section{Author's Contribution}

All authors contributed equally to the work.

PALAVRAS-CHAVE: Infecções por Coronavirus. Pandemias. Relações Médico-Paciente.

\section{REFERENCES}

1. Costa FD, Azevedo RCS. Empatia, relação médico-paciente e formação em medicina: um olhar qualitativo. Rev Bras Educ Med. 2010;34(2):261-9.

2. Gomes AMA, Caprara A, Landim LOP, Vasconcelos MGF. Relação médico-paciente: entre o desejável e o possível na atenção primária à saúde. Physis. 2012;22(3):1101-19.

3. Vallelonga F, Elia F. Doctor-patient relationship at the time of COVID-19: travel notes. Intensive Care Med. 2020;1. doi: 10.1007/s00134-020-06152-w.

4. Gao B, Dong J. Does the impact of COVID-19 improve the doctor-patient relationship in China? Am J Med Sci. 2020;S0002-9629(20)30231-7.

5. Azoulay E, Kentish-Barnes N. A 5-point strategy for improved connection with relatives of critically ill patients with COVID-19. Lancet Respir Med. 2020;8(6):e52. 